\title{
Trabajadores y sindicalismo en el Uruguay de la dictadura (1973-1985): bibliografía, fuentes y acervos documentales disponibles
}

\author{
Workers andunionismin Uruguay during the dictatorship (1973-1985): bibliography, sources and available \\ documentary collections
}

Sabrina Alvarez

Instituto de Ciencias históricas, Facultad de Humanidades y Ciencias de la Educación, Universidad de la República, Uruguay

s.alvarez.torres@fhuce.edu.uy

\author{
Álvaro Sosa \\ Facultad de Humanidades y Ciencias de la Educación, Universidad de la República, \\ Uruguay
}

\section{ReSUMEN:}

El artículo plantea una aproximación inicial, de carácter descriptivo y analítico, a la bibliografía y algunas de las fuentes y acervos documentales con que se cuenta en la actualidad para el estudio de los trabajadores y sindicalismo, y su relación con el Estado, durante la última dictadura uruguaya (1973-1985). Para ello se realizará una breve síntesis de la producción bibliográfica sobre el tema, haciendo énfasis en las fuentes documentales y orales que han sido utilizadas. Luego se describirán y analizarán las principales fuentes identificadas hasta el momento por los autores, teniendo como eje las experiencias, resultados y dificultades visualizadas en las investigaciones que sobre esta temática llevan adelante. Finalmente, a partir de lo trabajado, en las conclusiones se realizará una valoración general de la situación en el Uruguay respecto al estudio de los trabajadores y sindicalismo en dictadura, planteando nuevas preguntas, así como posibles líneas de trabajo a futuro.

Palabras ClaVe: Trabajadores, Sindicalismo, Estado, Dictadura, Uruguay.

\begin{abstract}
:
The article proposes an initial approximation, of a descriptive and analytical nature, to the bibliography, and some of the sources and documentary collections that are currently available for the study of workers and tradeunionism, and their relationship with the State, during the last Uruguayan dictatorship (1973-1985). To this end, it is presented a short summary of the bibliographic production on the subject, emphasizing the documentary and oral sources that have been used. Then, the sources identified by the authors are described and analyzed, taking as axis the experiences, results and difficulties visualized in the research carried out on this subject. Finally, the conclusions will be a general assessment of the situation in Uruguay regarding the study of workers and unionism in dictatorship, raising new questions, as well as possiblelines of work in the future.
\end{abstract}

KeYWORDS: Workers, Unionism, State, Dictatorship, Uruguay.

\section{INTRODUCCIÓN}

En la madrugada del 27 de junio de 1973 el presidente constitucional del Uruguay, Juan María Bordaberry, con el apoyo de parte del elenco político y de las FF.AA. dispuso la disolución de las cámaras legislativas, dando inicio a la dictadura cívico-militar. El régimen de facto se extendió hasta el 1 de marzo de 1985, cuando asumió como Presidente el Dr. Julio María Sanguinetti, quien meses atrás, en elecciones con decenas de ciudadanos proscriptos y presos políticos, había sido elegido para ejercer la primera magistratura.

La ruptura institucional fue el corolario de un proceso de agudización represiva protagonizado por el Estado uruguayo, cuyos orígenes se remontan a la década del cincuenta, siendo su etapa más álgida la iniciada a mediados de los sesenta. A partir del golpe de Estado el gobierno desarrolló un juego pendular en el que en determinadas coyunturas y frente a ciertos sectores del sindicalismo intentó construir alianzas 
y generar una base social, en otros casos estableció mecanismos de mediación en los conflictos laborales con un sentido paternalista y, finalmente, en muchas situaciones desplegó la más dura represión sobre trabajadores organizados. Como trasfondo de estas prácticas institucionales se evidencia el intento de control y disciplinamiento de la población necesarios para la aplicación de un modelo económico desfavorable para la mayoría de la clase trabajadora. Todo esto impactó en el sindicalismo y el conjunto de los trabajadores.

En el Uruguay la producción bibliográfica sobre trabajadores y sindicalismo en dictadura se encuentra en una etapa exploratoria. Las fuentes documentales son de difícil acceso y abordaje. Los testimonios orales, bastante más cuantiosos, deberían ser puestos en diálogo de modo más fluido con la bibliografía y fuentes. Asimismo, es necesario realizar una mayor cantidad de entrevistas que apunten a darle voz a sectores poco atendidos, como por ejemplo las mujeres, los militantes de base y los trabajadores del interior del país.

El presente artículo plantea una aproximación inicial, de carácter descriptivo y analítico, a algunas de las fuentes y acervos documentales con que se cuenta en la actualidad para el estudio de los trabajadores y el sindicalismo durante la última dictadura uruguaya (1973-1985). Se alimenta de los avances alcanzados en el marco del proyecto de investigación "Pensando el mundo sindical en dictadura (1975-1981). Cuatro estudios de caso" ${ }^{11}$, y tiene como su principal antecedente el trabajo desarrollado en el proyecto "Historia del Sindicato Único de la Construcción y Anexos (SUNCA)"2. Esta tarea nos ha permitido realizar una labor de campo que no solamente dio cumplimiento a los requerimientos iniciales del colectivo sindical, sino que posibilitó comenzar a estudiar de forma más profunda gran parte de la bibliografía y fuentes existentes a partir de preguntas y enfoques distintos a los desarrollados por otros investigadores.

En el primer apartado de este trabajo se presentan las principales líneas analíticas que han tenido los estudios sobre trabajadores, sindicatos y Estado en dictadura, destacando el énfasis puesto en las dimensiones políticas del fenómeno en detrimento de sus aristas socio-económicas, culturales, vinculares, de condiciones de trabajo y de legislación laboral. A partir de estas valoraciones se propone una posible periodización de la dictadura que tenga como eje el derrotero de los trabajadores y sindicatos, y sus vínculos con el Estado.

La segunda parte del trabajo presenta una breve síntesis de la producción bibliográfica sobre el tema, haciendo énfasis en las fuentes documentales y orales utilizadas por los diversos autores, haciendo patentes los avances y limitaciones del conocimiento de acuerdo a los abordajes realizados y las fuentes utilizadas. En tercer lugar se propone la descripción y análisis de las principales fuentes identificadas hasta el momento, a partir de las experiencias, resultados y dificultades visualizadas en las investigaciones que llevan adelante los autores del presente artículo. Por último se realizará una valoración general de la situación en el Uruguay de los estudios sobre trabajadores y sindicalismo en dictadura, planteando nuevas preguntas, así como posibles líneas de trabajo a futuro.

Finalmente, cabe destacar que no hemos accedido aún a la consulta de archivos empresariales, lo cual es sin duda materia pendiente de este trabajo. A pesar de ello consideramos que en buena medida a través de la lectura de fuentes producidas por el Estado y los actores sindicales y políticos es posible realizar un acercamiento inicial a la temática. Asimismo se trata de una dimensión que ha sido mayormente abordada que la referida a trabajadores, sindicatos y Estado, al menos desde la arena de los estudios económicos.

\section{ALCANCES Y LIMITACIONES DE LOS ESTUDIOS URUGUAYOS SOBRE TRABAJADORES Y SINDICATOS EN LA ÚLTIMA DICTADURA}

En general los estudios sobre la última dictadura en el Uruguay no han tenido a los trabajadores y las organizaciones sindicales como protagonistas. Su presencia en los diversos análisis sobre el período ha sido fragmentaria y por lo general concebida de forma tributaria de los procesos políticos y político-institucionales que se desarrollaban en el país.

Este fenómeno puede observarse tanto en los trabajos iniciales que desde diversas disciplinas buscaron realizar una labor de síntesis, ordenamiento e interpretación de hechos y procesos (González, 1985; 
Bruschera, 1986; Caetano y Rilla, 1987; Dutrenit Bielous, 1994; Guillespie, 1997), así como también en obras más recientes que, buscando incluir nuevos tópicos y protagonistas en el análisis del período, agruparon trabajos de diversos autores originarios de distintas disciplinas (Marchesi, Markarian, Rico Y Yaffé, 2004; Demasi, Marchesi, Markarian, Rico y Yaffé, 2013; Nahum, 2012).

La bibliografía consultada coincide en que tanto los trabajadores como el sindicalismo habrían tenido cierto protagonismo durante la dictadura únicamente en sus inicios y postrimerías. Se ha estudiado su actuación a lo largo de la huelga general desarrollada durante los quince días posteriores a la disolución de las cámaras legislativas ${ }^{3}$, así como a partir del 1 de Mayo de 1983, fecha en que se celebró en Montevideo un multitudinario acto organizado por el novel Plenario Intersindical de Trabajadores (PIT) ${ }^{4}$ que posicionó al movimiento sindical como un actor de peso en el proceso de transición político-institucional.

Las referencias a los trabajadores y sindicatos en el período que va desde el levantamiento de la huelga general el 11 de julio de 1973 a la celebración del 1 de Mayo de 1983 son escasas, pues su capacidad de acción y presencia pública se vio sensiblemente restringida. Si bien es cierto que muchos de los trabajos que abordan esta etapa hacen referencia al accionar colectivo-gremial en ámbitos laborales por reivindicaciones puntuales, y a la existencia de algunos núcleos clandestinos de militantes sindicales de diversas organizaciones, por lo general se trata de simples menciones, sin adentrarse en el estudio profundo de los fenómenos.

A su vez, si se piensa en la producción bibliográfica que específicamente centra su análisis de forma parcial o total en el estudio de los trabajadores y sindicatos en dictadura, lo hace partiendo casi exclusivamente de la realidad montevideana, con muy pocas referencias a la forma en que los trabajadores vivieron el período en el interior del país 5 .

Por otra parte, se trata de trabajos que por lo general ponen énfasis en el análisis de las corrientes políticosindicales presentes en el seno de las organizaciones obreras, las que generalmente son concebidas en relación de dependencia con las estructuras políticas externas a los sindicatos (partidos, grupos armados, frentes de masas, etc.).

Estos enfoques parecen deberse al peso de la historia política en la producción bibliográfica uruguaya y a las dificultades de concebir a los trabajadores y sindicatos más allá de las dimensiones político-institucionales y político-partidarias. De esta forma se olvida el impacto de lógicas coyunturales (a nivel político o socioeconómico), culturales, vinculares, de condiciones de trabajo, de legislación laboral, etc., que afectan en las diferentes acciones y decisiones de los trabajadores. A su vez, estos estudios se centran en establecer grandes hitos o acontecimientos de los cuales son protagonistas las corrientes político-sindicales, los militantes y dirigentes; dejando de lado una historia que a simple vista parece menos heroica, constituida por expresiones cotidianas, desarrolladas en espacios acotados. Esto provoca que la historia de los trabajadores se confunda con la historia de las corrientes político-sindicales y sus élites militantes y dirigentes.

La jerarquización de estas dimensiones de la política en el estudio de los trabajadores y sindicatos en dictadura hace también que al momento de ensayar una periodización general de sus itinerarios se utilice la propuesta elaborada por Luis E. González décadas atrás (1985). Esta plantea una división tripartita del período de facto: "dictadura comisarial" (1973-1976), “ensayo fundacional" (1976-1980) y "dictadura transicional" (1980-1985). La misma fue estructurada en base a los principales cambios políticoinstitucionales vividos por el régimen, por lo que no parece del todo funcional al momento de estudiar el devenir de fenómenos sindicales y aquellos de la vasta clase trabajadora. Esto no significa negar la influencia de los procesos político-institucionales en la vida de los trabajadores y sindicatos, pero sí cuestionar su carácter de dimensión excluyente al momento de analizarlos, y por tanto periodizarlos.

Sin contar aún con todos los elementos que nos permitan elaborar una propuesta acabada de periodización de la dictadura que tenga como factor central la situación de los trabajadores, las organizaciones sindicales y la relación de ambos con el Estado, y siendo conscientes de que cada sindicato vivió experiencias propias que marcaron su itinerario particular, proponemos aquí algunos ejes prioritarios a partir de los que pensarla. 
Durante la huelga general el gobierno de facto consideró a los sindicatos como interlocutores con los cuales negociar diversos aspectos laborales y hasta político-institucionales (Demasi, 2013, p. 38). Esta posición se mantuvo luego de que la medida de huelga fuera levantada, pero el gobierno dictatorial aumentó la apuesta y consideró la posibilidad de reorganizar el sindicalismo prescindiendo de las corrientes mayoritarias dentro de la Convención Nacional de Trabajadores (CNT), con el fin de construir una central sindical "nacionalista" y anticomunista. Si bien durante este período inicial muchos dirigentes sindicales sufrieron la tortura y la cárcel, la posición oficial fue la de tolerar, y en algún caso promover la actividad sindical, buscando construir a partir de ella una base social (Morón, 2003, pp. 12-16, 23-27; Alvarez y Sosa, 2014a). Este proyecto tuvo varios reveses por parte de la mayoría de la dirigencia y militancia sindical, que no apoyó de la manera esperada las propuestas gubernamentales, y hacia inicios de 1974 la idea de una "central nacionalista" era dejada de lado por el gobierno ante la aparición de lo que se denunciaba como una "nueva infiltración marxista" que impedía la concreción de las propuestas planteadas (Morón, 2003, p. 27).

En este marco, a partir de la segunda mitad del año 1974, recrudeció la represión hacia las organizaciones sindicales. Son ejemplo de ello la ilegalización del SUNCA en octubre de ese año (Alvarez y Sosa, 2014b) y de la UNTMRA en agosto de 1975 (García, 2016, p. 301).Pero fue desde octubre de 1975, con la instrumentación de la "Operación Morgan", que se inició el período represivo que tuvo mayores repercusiones en el movimiento sindical uruguayo. Con ella fue desarticulada la dirección clandestina de la CNT y buena parte de la estructura de diversas organizaciones sindicales. De allí en más la actividad de los sindicatos que sobrevivieron fue básicamente clandestina, atomizada y centrada en actividades de propaganda, finanzas y apoyo a las familias de los militantes presos o desaparecidos (Alvarez y Sosa, 2015). Asimismo, durante el período se dieron varios ejemplos de acciones impulsadas por trabajadores en diversos centros laborales con el fin de alcanzar reivindicaciones puntuales. Estas actividades a veces estaban asociadas a la labor clandestina de militantes de las organizaciones cenetistas que lograban escapar a la represión. Otras, inferimos, pueden haber respondido al accionar inorgánico de trabajadores.

El ostracismo en el que cayó la actividad sindical pública vio su fin hacia finales de 1981, cuando el régimen aprobó la ley de Asociaciones Profesionales que, con serias limitaciones, permitía la creación de organizaciones de trabajadores. La Asociación de Empleados Bancarios del Uruguay (AEBU) (que gracias a una ingeniosa combinación de actividad gremial con propuestas sociales, deportivas y culturales había logrado permanecer en la legalidad) fue el primer sindicato en acogerse a la ley en diciembre de ese año. Le siguieron una cantidad importante de organizaciones que bajo variados formatos intentaron aprovechar las posibilidades que abría la norma. Varios de ellos fundaron de cara al 1 de Mayo de 1983 el PIT, que debió convivir con una CNT que actuaba clandestinamente en Uruguay y que contaba además con una cantidad importante de dirigentes y militantes organizados en el exilio como "CNT en el Exterior". Si bien la relación entre el PIT y la CNT fue en líneas generales armónica, ya que en muchos casos ambas estructuras estaban constituidas por militantes de las mismas organizaciones políticas y sociales, sí existieron algunos desencuentros que intentaron ser laudados con la unificación, luego del 1 de Mayo de 1984, en el PIT-CNT (Rodríguez, Chagas y Ladra, 1991; Chagas y Tornarelli, 1989, pp. 219-245). Hacia fines de 1984 la mayoría de los sindicatos estaban legalizados y aquellos que habían perdido sus locales sindicales los recuperaban.

Considerando lo antedicho se puede pensar en una primera etapa que se desarrolló desde el golpe de Estado y la huelga general hasta mediados de 1974-1975, cuando la represión se endureció y la mayoría de las organizaciones sindicales vieron seriamente limitadas sus posibilidades de desarrollar una actividad pública. Esta segunda etapa transcurrió hasta fines de 1981, cuando AEBU decidió acogerse a la Ley de Asociaciones Profesionales, iniciándose un proceso de reorganización legal de los sindicatos. Este último período se cerró a fines de 1984 con la legalización formal o de hecho de las diversas organizaciones cenetistas, en el marco de un movimiento sindical que se había unificado producto de la concreción del PIT-CNT. 


\section{BREVE RESEÑA SOBRE LA PRODUCCIÓN BIBLIOGRÁFICA Y LAS FUENTES UTILIZADAS}

Los primeros abordajes respecto al papel de los trabajadores y las organizaciones sindicales en dictadura fueron planteados desde el campo de la sociología y la ciencia política. Se trataba de trabajos que, considerando la trascendencia que los movimientos sociales habían ganado durante la transición, proponían una mirada de largo plazo que observara la relación existente entre los sindicatos y el Estado, las organizaciones políticas y los empresarios a lo largo del siglo XX. El objetivo era analizar la forma en que ingresaba el movimiento sindical a la democracia y el papel que jugaría en ella como factor político.

El fin central no era el estudio de los trabajadores y sindicatos en dictadura, a pesar de lo cual aparecían algunas referencias sobre la existencia de estructuras clandestinas mínimas, generalmente vinculadas a organizaciones político-partidarias también clandestinas, que entre 1974 y 1983 desarrollaron actividades especialmente de carácter propagandístico.La acción de los trabajadores era mirada en clave políticoinstitucional y político-partidaria. Dejando en segundo lugar las otras dimensiones del fenómeno, o considerándolas tributarias del análisis antedicho.

En esta etapa inicial el trabajo con fuentes primarias se centró en el análisis de publicaciones de prensa de la época y de la legislación producida por el régimen. Su principal objetivo era reconstruir e interpretar los procesos históricos. Se destacan el temprano trabajo de Romeo Pérez Antón (1981), así como las publicaciones de Martín Gargiulo (1984), Gustavo Cosse (1985), Jorge Lanzaro (1986), Alfredo Errandonea (1986) y Francisco Pucci (1992).

De forma simultánea se comenzaban a producir por parte de historiadores profesionales e "historiadores militantes" (Porrini, 2004, p. 164) obras que estudiaban al sindicalismo uruguayo en general o algunas de sus organizaciones en particular. Estos trabajos, que en buena medida aún se sostenían en el análisis de prensa y legislación, comenzaron a integrar algunas fuentes, todavía escasas y desordenadas, producidas por las organizaciones sindicales o corrientes político-sindicales dentro de Uruguay y en el exilio, como ser documentos, declaraciones y boletines. También en algunos casos realizaron entrevistas a dirigentes gremiales de la época. Se destacan las síntesis históricas sobre el movimiento sindical uruguayo elaboradas por Jorge Landinelli y Lucía Sala (1984) y Yamandú González Sierra (1989), los trabajos sobre Acción Sindical Uruguaya (ASU) ${ }^{7}$ de José R. Bottaro (1985) y Gley Eyherabide (1993), y la historia de AEBU de Héctor Ruíz Valente (1992). Una referencia especial merece la obra de Jorge Chagas y Jorge Tornarelli (1989), hasta hoy el único trabajo que de forma exclusiva aborda el estudio del sindicalismo uruguayo a lo largo de todo el período de facto, utilizando para ello una importante variedad de fuentes orales y escritas (prensa, legislación del régimen, documentación producida por sindicatos y militantes gremiales dentro y fuera del país).

La derrota en el plebiscito de 1989 de la opción que proponía llevar ante la justicia a los responsables de las violaciones a los derechos humanos tuvo un fuerte impacto en ámbitos de la izquierda, los movimientos sociales y la academia, generando una suerte de interrupción en las investigaciones y debates que desde años atrás se desarrollaban en relación con la década del sesenta, setenta y ochenta (Marchesi y Markarian, 2012, p. 224). Como consecuencia de esto también disminuyó sensiblemente la producción historiográfica respecto de trabajadores y sindicatos en dictadura.En este período se produjeron mayoritariamente memorias, historias de vida o biografías elaboradas a partir de los recuerdos y vivencias de sindicalistas, las que venían a sumarse a algunas otras publicadas en la segunda parte de la década de 1980 (Turiansky, 1987; Masi, 1989; Fernández Huidobro, 1995, Bouzas, 1997; Chagas y Trullen, 1998). Cabe destacar que en la mayoría de los casos se trató de obras que aportaban información parcial para el estudio de los trabajadores y sindicatos, pues la mayoría de sus protagonistas fueron encarcelados o debieron partir al exilio en los primeros años del régimen de facto.

También en este período vieron la luz dos trabajos que ponían el énfasis en la entrevista como insumo para el estudio del sindicalismo en el período dictatorial. Por un lado la obra de Roger Rodríguez, Jorge Chagas y Antonio Ladra (1991), que a medio camino entre el ensayo periodístico y el trabajo historiográfico intentó 
repasar la fundación y desarrollo del PIT durante los años 1983 y 1984. En segundo lugar, el antropólogo Álvaro de Giorgi (2000) describió el itinerario del sindicalismo uruguayo en dictadura, prestando especial atención a la dimensión subjetiva al analizar los factores identitarios que se configuraron y reconfiguraron en el marco de acciones colectivas de diverso tipo.

Desde inicios del presente siglo investigadores de la Universidad de la República (UdelaR), en varios casos a solicitud de organizaciones sindicales rastrearon, sistematizaron y ordenaron fuentes producidas por los sindicatos a lo largo de su existencia, incluyendo la dictadura. En algunos casos estas experiencias tuvieron como resultado la conformación de archivos en los locales sindicales. Así, un equipo dirigido por el investigador Rodolfo Porrini trabajó en el relevamiento y descripción de colecciones documentales correspondientes a cuarenta y seis sindicatos, logrando en varios casos su organización y ordenamiento (Porrini, 2004); en el archivo de la Unión Nacional de Trabajadores Metalúrgicos y Afines (UNTMRA) trabajaron las investigadoras Evana Alfonso e Isabel Wschebor primero, y un equipo dirigido por Susana Dominzain después (Alfonso y Wschebor, 2000; Dominzain, 2016); y otro equipo, en este caso dirigido por Carlos Demasi, sistematizó y organizó el archivo de la comisión de la memoria del Sindicato Único de la Construcción y Anexos (SUNCA) (Álvarez y Sosa 2014a, 2014b, 2014c, 2015, 2017).Esto permitió reunir boletines, declaraciones, volantes y otros documentos, muchos de ellos producidos en clandestinidad o en el exterior, a los cuales se había tenido escaso acceso.

Estos mismos proyectos, u otros generados desde diversos ámbitos, mostraron especial preocupación por recabar fuentes orales. En muchos casos las entrevistas dejaron de enfocarse únicamente en los dirigentes, y comenzaron a escucharse con mayor asiduidad las voces de los militantes de base, las sindicalistas mujeres o los referentes y militantes del interior del país.Esta renovación de fuentes enriqueció el estudio de los trabajadores y sindicatos durante la dictadura al sumar las visiones de protagonistas hasta ese momento ignorados, incluir dimensiones de estudio vinculadas al fenómeno de la cotidianeidad, permitir pensar la acción sindical en clave territorial y geográfica (barrio, localidad, pueblo, ciudad), poner sobre la mesa problemas como la complejidad del rastreo de la acción sindical en clandestinidad, su naturaleza y el carácter de los vínculos que los sindicatos ilegales tejieron con las organizaciones políticas en similar condición.Pero, por otro lado, esto también conllevó el peligro de que ese relato se dejara teñir por la "épica de la resistencia" presente en documentos que en muchos casos tenían entre sus objetivos específicos impregnar a los trabajadores y militantes sindicales y políticos de optimismo y esperanza, o en entrevistas donde la heroicidad tiende a transformarse en componente central del relato de quien brinda el testimonio.

Otro aporte sustancial fue realizado por el equipo universitario dirigido por Álvaro Rico, que a partir del requerimiento de la Presidencia de la República analizó una importante cantidad de documentación producida por diversos organismos represivos del régimen a la cual hasta el momento no se había tenido acceso. El trabajo permitió reconstruir las principales características de la represión desatada contra el movimiento sindical uruguayo en dictadura (Rico, 2008, pp. 183-285). Asimismo, el conjunto de estas nuevas fuentes sirvieron de materia prima para dar respuesta a una creciente demanda de estudios de organizaciones sindicales puntuales, en algunos casos desde sus orígenes hasta la posdictadura, y en otros centrados exclusivamente en el período de facto. Estas historias fueron elaboradas por militantes de la organización estudiada o por autores externos (historiadores, periodistas, ensayistas) a solicitud de esta. El relato pretendía englobar la acción de la organización sindical analizada en el marco de una amplia resistencia colectiva (impulsada por el "movimiento sindical" o el "movimiento popular").

En este grupo de trabajos incluimos obras sobre el sindicato de trabajadores de las Fábricas Nacionales de Cerveza (José López Mercao, 2004), AEBU (Juan Pedro Ciganda, 2007), la Unión de Obreros Curtidores (García, 2010), la Asociación de Funcionarios Postales del Uruguay (Alvarez, Cuello y Poloni Porras, 2014), la Federación Uruguaya de la Salud (FUS, 2015), la Confederación de Organizaciones de Funcionarios del Estado (Girona y Siola, 2016), la UNTMRA (García, 2016) y el SUNCA (Rodríguez y Visconti, 2008; Alvarez y Sosa, 2014a, 2014b, 2014c, 2015, 2017). 
Estas nuevas fuentes también aportaron al estudio del sindicalismo en coyunturas puntuales de la dictadura. Por ejemplo, Alicia Morón (2003) analizó las políticas impulsadas por el gobierno entre los años 1973 y 1976 frente a una doble necesidad: reprimir las formas de acción colectiva que suponían espacios de resistencia, y habilitar mecanismos que posibilitaran la canalización de reclamos de los trabajadores. Con este fin la autora trabajó, entre otras fuentes, con legislación laboral, series producidas por el Ministerio de Trabajo y Seguridad Social y documentos preservados en el Archivo Etcheverry Stirling ${ }^{8}$.

El equipo conformado por Álvaro Rico, Carlos Demasi, Rosario Radakovich, Isabel Wschebor y Vanesa Sanguinetti (2005) analizó los quince días de huelga general con la que el movimiento sindical respondió al golpe de Estado del 27 de junio de 1973, así como sus antecedentes y principales derivaciones. Esta obra se sustentó en un importante trabajo con fuentes éditas e inéditas, así como en varias entrevistas a dirigentes y militantes sindicales.

Finalmente el libro Gol del pueblo uruguayo reconstruye elementos del período 1979-1982 a partir de la transcripción de documentación producida por varias organizaciones sindicales y de la realización de entrevistas a militantes vinculados al SUNCA, la UNTMRA y la CNT. Sus autores prefirieron presentarse como Autores Anónimos (2012) por considerar que se trata de una obra de autoría colectiva al relatar pasajes de una lucha antidictatorial que tuvo a miles de uruguayos como protagonistas.

Tanto los documentos allí publicados, generalmente recopilados por los autores en archivos personales o, en menor medida, en repositorios institucionales como el archivo del SUNCA, como los testimonios recabados, permiten acercarse desde el punto de vista de los militantes clandestinos a diferentes aspectos del período dictatorial, así como las preocupaciones y lógicas de funcionamiento del sindicalismo clandestino

Por otro lado la historia general del sindicalismo uruguayo de Universindo Rodríguez, Silvia Visconti, Jorge Chagas y Gustavo Trullen (2005) utiliza también nuevas entrevistas para enriquecer el relato sobre el período dictatorial.

El reciente artículo del historiador Rodolfo Porrini (2005), si bien no suma nuevas fuentes, propone una interesante síntesis de las principales características de las temáticas abordadas por la historiografía uruguaya respecto al sindicalismo en dictadura, así como los problemas que los nuevos estudios deben abordar sobre el tema. Entre ellos incluye ahondar en el estudio de las características de las clases trabajadoras en dictadura, profundizar en las formas de expresión que los trabajadores construyeron, ya fuera en clave de resistencia o consenso, conocer los factores que influyeron en las acciones y decisiones tomadas por los núcleos sindicalpolíticos organizados que reconocían la continuidad y representatividad de la CNT y sus sindicatos, así como estudiar las polémicas que los atravesaron durante el período, e intentar traducir lo heterogéneo de la realidad de la época, poniendo en juego lo territorial y geográfico (barrio, localidad, pueblo, ciudad) como elementos centrales que influyeron en las opciones y decisiones tomadas por individuos y colectivos. Finalmente es de destacar que desde la década de 1980 varios abogados laboralistas describieron y analizaron las transformaciones que en materia de legislación se procesaron durante el período de facto. En este marco se mencionan instancias de negociación bipartita que serían dignas de estudio, como el caso de los "seguros convencionales" que se habrían conformado en varios sectores de la industria y el comercio. (Ermida Uriarte y Grzetich, 1991).

Para el estudio de las transformaciones sufridas por la clase trabajadora durante la dictadura resultan claves los análisis que desde la economía se han realizado, a pesar de que muchas veces privilegian los enfoques macroeconómicos en los que los detalles que más interesan al historiador se pierden. Se destacan los aportes realizados a partir del estudio de fuentes estadísticas (Notaro, 1984 y 2003; Cancela y Melgar, 1985; Azar, García Repetto, Bertoni, Sanguinetti, Sienra, 2009; Mariño, Noboa y Parada, 2009; Fleitas y Román, 2010), así como también aquellos que se refieren al desarrollo de los distintos sectores de la economía (Macadar, 1982; Camou, 2006; Camou y Maubrigades, 2007). Estos análisis permiten ensayar hipótesis respecto a las relaciones de patronales, trabajadores, organizaciones sindicales y agentes del Estado. Por desgracia la mayoría de los estudios sobre trabajadores y sindicatos dialogan escasamente con estas interpretaciones. Una 
excepción es el trabajo pionero del periodista Miguel Carrió (1987), quien denunció la connivencia del régimen de facto con sectores empresariales favorecidos por la política económica del régimen.

Por su parte, Alicia Morón, en un artículo referido anteriormente, maneja ejemplos de legislación laboral y documentación producida por el Ministerio de Trabajo y Seguridad Social de la época que dan cuenta de la política del régimen hacia el mundo del trabajo, y de la forma en que empresarios y asalariados se relacionaron con ella. Por último, la obra colectiva dirigida por el investigador argentino Juan Pablo Bohoslavsky (2016) propone algunos marcos interpretativos iniciales para entender los vínculos entre el gobierno de facto y el empresariado local y transnacional, así como la responsabilidad que a este le cupo en el plan sistemático de violación a los derechos humanos.

Las principales novedades que presentan los trabajos allí publicados refieren a la financiación del terrorismo de Estado por parte del capital transnacional; la postura oscilante del empresariado local, que pasó de aplaudir la "tranquilidad laboral" que aseguraba el régimen a "reciclarse" en la transición como parte del frente antidictatorial; los delitos económicos y episodios de corrupción que se dieron en dictadura con la participación o el beneplácito de las autoridades; la alianza que el gobierno tejió con los medios de comunicación a partir del intercambio de favores; y la responsabilidad jurídica a nivel del derecho internacional y uruguayo que le cabe al empresariado colaboracionista .

\section{Fuentes Disponibles y SUS POSIBLES USOS. AlgunOS DESAFÍOS METODOLÓGICO-TÉCNICOS}

Para hablar de los testimonios orales y las fuentes documentales sindicales partimos de lo que ha sido nuestra participación en el proyecto de investigación "Historia del Sindicato Único de la Construcción y Anexos (SUNCA)", ya referido en la introducción del presente artículo. En este proyecto se trabajó conjuntamente con la Comisión de la Memoria del SUNCA integrada principalmente por viejos militantes del sindicato que protagonizaron los hechos a relatar. Esta dinámica significó una serie de desafíos específicos que se intentaron subsanar con una constante reflexión sobre la propia práctica, tratando de mantener siempre presentes los límites entre Historia y memoria(s) y el respeto a la demanda de los actores sociales con los que se trabajó.

El proyecto tenía la pretensión de realizar una mirada de todo el Uruguay, pero salvo algunos aspectos puntuales, el acercamiento se concentró principalmente en el contexto montevideano y en algunas ciudades del interior del país con una importante densidad de trabajadores de la construcción, como Salto y Punta del Este. De todos modos se pudieron recuperar, en especial a través de testimonios orales, relatos sobre la situación en el interior que dan cuenta de las diferencias entre este heterogéneo espacio geográfico y la capital del país.

A partir de esta primera experiencia de investigación nos propusimos profundizar en el estudio de trabajadores y acciones colectivas/sindicales en el período 1975-1981 observando otros casos a fin de contrastar. La primera parte de este proceso se destinó a la elaboración de un estado de la cuestión lo más exhaustivo posible. La segunda etapa, en pleno desarrollo, está centrada en el relevamiento de fuentes para el estudio del período. Partiendo de esto, exponemos una serie de consideraciones sobre un interesante abanico de insumos éditos e inéditos que pueden aportar a un mejor conocimiento de la temática en cuestión.

Es de destacar que además del SUNCA existen otros ejemplos de sindicatos que poseen algún tipo de repositorio documental, como son AEBU, la UNTMRA, la Asociación de Funcionarios Judiciales del Uruguay, la Unión Ferroviaria y la Unión de Empleados, Obreros, y Supervisores de FUNSA. En la mayoría de estos casos la documentación referida al período dictatorial es escasa o nula, siendo la excepción el archivo del sindicato de trabajadores de la empresa FUNSA, que posee documentación sobre el período 1983-1985.

Finalmente, también es necesario hacer referencia a aquellos acervos documentales de carácter institucional que guardan algunos materiales vinculados a los trabajadores y sindicatos en dictadura, como son el Archivo de Propaganda Política del Departamento de Historiología de la FHCE de la UdelaR y el 
Archivo del Centro de Estudios Interdisciplinarios Uruguayos (CEIU), radicado también en FHCE de la UdelaR.

\section{Los testimonios orales}

El proyecto de trabajo sobre el SUNCA tenía como uno de sus principales objetivos la "recuperación" de la memoria del colectivo sindical respecto del período de facto, conjugado con el anhelo de los sindicalistas de transmitir a las nuevas generaciones de militantes aquellas experiencias. A su vez, la escasez de fuentes documentales producidas por los protagonistas hizo que los testimonios orales se transformaran en un insumo central para la investigación.

Se realizaron más de cien entrevistas. La mayoría de los entrevistados (casi todos varones) fueron o son miembros del Partido Comunista de Uruguay (PCU), aunque se identificaron también algunos pocos militantes vinculados a otras organizaciones de izquierda como el Partido Socialista, el Movimiento de Liberación Nacional-Tupamaros, el Partido por la Victoria del Pueblo y los Grupos de Acción Unificadora. Todos ellos, de una manera u otra, habían sufrido la persecución dictatorial.

Se identificó como elemento más o menos compartido en los relatos cierta carga "épica" que, según entendemos, les ha servido como mecanismo para procesar lo traumático de la experiencia vivida. La visión épica de lo acaecido lleva en algunos casos a la sobredimensión de ciertos episodios y su alcance. (Alvarez y Sosa, 2016).

Las memorias, elaboradas intersubjetivamente, nunca son estrictamente individuales sino que se alimentan de las interacciones con otros actores a través de vivencias compartidas. Los testimonios de estos militantes respecto de una época especialmente significativa en sus vidas dan cuenta de una constante identificación con sus experiencias en el marco de la acción político-partidaria. (Alvarez y Sosa, 2016, 2017).

$\mathrm{Si}$ bien las preguntas realizadas a los entrevistados apuntaban especialmente a conocer aspectos diversos de su militancia sindical clandestina en una coyuntura donde las acciones de este tipo eran duramente reprimidas, aparecen también en sus relatos menciones a situaciones vividas en sus lugares de trabajo, a reuniones celebradas con los militares, a las características de la represión y su impacto en la vida cotidiana, entre otras.

Aportan miradas a escala micro de pequeñas acciones de resistencia al régimen en las que no había un límite claro entre aquellas netamente "sindicales" y las que eran de carácter "político".

Por otra parte, las vivencias que los entrevistados tuvieron con posterioridad a los hechos relatados influyen directamente en su percepción de ese pasado. Dado el énfasis asignado en el proyecto al trabajo con fuentes orales y la trascendencia que para los entrevistados tenía que sus relatos sirvieran de "ejemplo" para las generaciones que no vivieron el período de facto, en muchos casos priorizamos esta voluntad expresada por viejos y nuevos militantes del sindicato y jerarquizamos una interpretación de los hechos que en ocasiones se sustentaba más en la memoria que en las formas esperadas de la investigación historiográfica.

Entendemos que estas fuentes brindan valiosa información respecto de las percepciones y recuerdos de los entrevistados. A la hora de utilizarlas en el marco de una investigación en profundidad deben ser criticadas y ponderadas tomando otros recaudos que, como ya dijimos, permitan extraer de las mismas los datos y valoraciones que nos posibiliten aproximarnos más y mejor a lo que acaeció. Es necesario por tanto tomar tres recaudos básicos (de los que se desprenden otros sucedáneos) consistentes en considerar el lugar de enunciación del entrevistado (trayectorias individuales y colectivas), el vínculo que se genera con el entrevistador y las proyecciones imaginadas del relato enunciado en relación con las implicancias que pueda tener lo que dicen'.

Creemos que la construcción de fuentes orales es no sólo un recurso fundamental para el acceso al pasado reciente, sino también un medio de democratización de la palabra y de elaboración de las experiencias 
traumáticas vividas durante los últimos períodos represivos. En ese sentido tienen un valor en sí que excede los objetivos de cualquier investigación, vinculándose al compromiso con la lucha por el respeto de los derechos humanos, la justicia, la reparación y el nunca más.

\section{Acervos documentales sindicales. El archivo de la comisión de la memoria del SUNCA}

En primer lugar cabe mencionar que hasta el momento hemos encontrado pocas fuentes producidas por el SUNCA clandestino y trabajadores de la construcción. Las existentes ofrecen discursos que entremezclan concepciones sindicales con visiones de la realidad producidas desde las izquierdas, en especial el PCU. Esto podría deberse por un lado a la doble militancia (sindical y política) desarrollada por quienes produjeron los materiales; así como al predominio de visiones que concebían la acción sindical supeditada al objetivo político considerado prioritario: la lucha antidictatorial.

Varios de los militantes que participaron en la confección y distribución de los materiales clandestinos concuerdan en afirmar que estos tenían como principal objetivo mantener comunicados a diversos sectores críticos con el régimen. Transmitían la idea de que existía toda una estructura sindical organizada "en racimo", con una dirección capaz de orientar a una masa relativamente numerosa de militantes clandestinos y de organizar aparatos de prensa, propaganda y finanzas de una forma relativamente similar a la vida en legalidad. Esta visión parece en parte responder mucho más a una pretensión que a la realidad, aunque tenga un anclaje en ella. Fueron un elemento más de resistencia y de cohesión. A pesar de ello, de su análisis se decanta importante información.

En el archivo del SUNCA hay piezas documentales producidas en dictadura por el sindicato de la construcción, el Centro Obrero de la Industria del Ascensor, la CNT y el PIT. ${ }^{10}$

Como se puede observar, las fuentes documentales existentes son escasas. A pesar de ello es de destacar la importancia de su existencia, ya que la intención de reunir documentación histórica no es especialmente frecuente entre las organizaciones sindicales. En este sentido, el rastreo y selección inicial que la propia organización hizo fue un buen punto de partida, a sabiendas de que, seguramente, la misma respondió a intereses distintos a los que puede perseguir la investigación histórica.

Por otra parte dentro del archivo hay varios documentos emitidos por los ministerios de Defensa e Interior a solicitud de familiares o víctimas directas del terrorismo de Estado con el fin de acogerse a las leyes de reparación. En estos puede encontrarse información sobre los mecanismos represivos desatados por el régimen contra las organizaciones gremiales, así como referencias a la actividad sindical y política desarrollada por militantes detenidos. También en algunos casos es posible hallar documentación sindical transcrita o adosada.

Asimismo, existen en el archivo varios recortes de prensa de la década de 2010 que recogen información sobre militantes y obreros de la construcción detenidos-desaparecidos. Estos permiten un cierto seguimiento de las causas judiciales en busca de verdad y justicia, así como un acercamiento a la vida de estos trabajadores antes de transformarse en víctimas del terrorismo de Estado.

Entendemos que el archivo en constante construcción es una expresión de la memoria de quién lo constituye. Da cuenta de su pasado, pero sobre todo de su presente en relación con proyecciones a futuro. Silencia o magnifica. Selecciona. Se usa y se puede hasta abusar de su contenido en virtud de los intereses que entran en juego. Todo esto debe ser tenido en cuenta a la hora de emplear las fuentes disponibles y complementarlas con otras.

Hay todo un trabajo por realizar en articulación con las organizaciones sindicales. El PIT-CNT ha expresado en reiteradas ocasiones su voluntad de luchar por la verdad, la justicia y la reparación de víctimas del terrorismo de Estado. Una de las principales prácticas en este sentido ha sido el intento, aún parcial, de construir un relato desde el movimiento sindical respecto de su propia historia (mucho de lo producido fue 
publicado en distintos órganos de divulgación). Para ello algunas organizaciones sindicales han recurrido a ensayistas e investigadores. Asimismo, en el último tiempo se ha dado un avance significativo con la creación del "Centro documental del PIT-CNT". Este se encuentra en su fase inicial, por lo que el acceso a la documentación que contiene es aún restringido.

Sin embargo, no se puede decir que haya una política sistemática y unificada en la materia; sino que queda relegada a un segundo plano (algo entendible considerando la diversidad de asuntos que de forma cotidiana deben atender) y bajo responsabilidad de cada una de las organizaciones sindicales. De todos modos, considerando las experiencias en otros países, son de saludar los esfuerzos que se vienen realizando. Creemos que el tema debe ser incorporado a la agenda sindical de modo mucho más sistemático. Más aún en los tiempos que corren donde se ha producido a nivel regional y mundial un retorno a tendencias conservadoras y autoritarias que identifican al movimiento sindical como uno de sus principales adversarios..

\section{Documentación producida por las cooperativas de viviendas por ayuda mutua. El archivo de la Cooperativa de Viviendas del SUNCA (COVISUNCA)}

Varias de las cooperativas nucleadas en la Federación Uruguaya de Cooperativas de Vivienda por Ayuda Mutua (FUCVAM) ${ }^{11}$ fueron un centro de la resistencia antidictatorial. Muchas estaban en proceso de construcción al darse el golpe de Estado, y continuaron a pesar de las limitaciones que pretendió imponerles el régimen (González, 2013).

En la mayoría de los casos las cooperativas de vivienda tenían un vínculo histórico con el movimiento obrero, varias poseían una matriz sindical (como el caso del COVISUNCA) y entre los cooperativistas había gran cantidad de militantes gremiales. Por tanto, cuando en dictadura la represión recrudeció las cooperativas se transformaron en lugar de cobijo para sindicalistas perseguidos, así como espacio de producción de propaganda clandestina (Alvarez y Sosa, 2015, pp. 39-42).

Asimismo, fueron protagonistas de importantes "hitos" de la lucha antidictatorial, como la exitosa campaña de recolección de firmas en contra de la ley de propiedad horizontal de noviembre de 1983, que posicionó al movimiento cooperativista en el centro de la escena de la resistencia a la dictadura junto con otros "nuevos movimientos sociales" (Guerrini, 1989, p. 91; Midaglia, 1989, p. 122).

La ley nacional de viviendas de 1971, que regía el funcionamiento de las cooperativas de vivienda por ayuda mutua, estableció como obligatoria la realización de asambleas periódicas de sus integrantes, la designación de comisiones y el registro de las actividades realizadas. Si bien las cooperativas no pudieron escapar de la vigilancia del régimen (por lo cual aportan información limitada), es de destacar que produjeron documentación a lo largo de todo el período dictatorial, entre las que sobresalen las actas de Asamblea y Comisión directiva.

En el marco del proyecto que venimos tomando como referencia se realizó un acercamiento primario a la actual secretaría del COVISUNCA que resguarda actas de asambleas y reuniones del consejo directivo durante el período dictatorial. Asimismo, dentro del archivo de la comisión de la memoria del SUNCA se encontraron boletines producidos por la propia cooperativa y por el instituto de asistencia técnica que la asesoraba.

Las cooperativas fueron también un espacio desde donde se tejieron redes de colaboración y solidaridad más allá de los aspectos específicamente vinculados a la vivienda. Así, por ejemplo, desde en 1977 existía en el COVISUNCA una cooperativa de consumo denominada El ceibo, la cual tenía como fin que los vecinos pudieran adquirir bienes a bajo costo en un contexto de constante aumento de precios de la canasta básica ${ }^{12}$.

En teoría, todas las cooperativas de vivienda deberían contar con documentación de este tipo ya que son necesarias para su gestión y administración cotidiana hasta la actualidad. En este sentido representan un prometedor acervo, hasta el momento inabordado, que podría dar cuenta de la vida cotidiana de los 
cooperativistas; del papel social y laboral jugado por las mujeres y los niños; de la importancia de las cooperativas como espacios de articulación de resistencia antidictatorial y cobijo para los perseguidos por el régimen; de las relaciones que estas tejieron con los barrios y localidades en los que se asentaban, entre otras cuestiones (González, 2013, p. 22). Considerando que en este caso también hablamos de documentación producida en un contexto de intensas restricciones a las libertades públicas y control policíaco, deben ser leídas con las precauciones del caso.

\section{Documentación estatal}

La hay édita e inédita. Dentro del primer grupo se destaca la labor realizada por el equipo de historiadores de la UdelaR dirigido por Álvaro Rico (Rico et al., 2005) mencionado páginas atrás. Si bien el trabajo fue elaborado con el fin de contribuir a la lucha por verdad y justicia, si se la interroga de otras formas puede aportar al conocimiento del pasado en relación al tema que nos interesa ${ }^{13}$.

A partir de su lectura es posible identificar a los militantes sindicales detenidos y desaparecidos, así como a las organizaciones a las que pertenecían.Además, la información permite buscar "patrones" entre los tipos de operativos y las personas detenidas y desaparecidas a partir de ellos.

Con el fin de ilustrar la metodología de persecución y seguimiento a las actividades sindicales por parte del régimen, así como las valoraciones que este realizaba sobre ellas, es que en el tomo III de su trabajo, en la sección titulada "La represión al movimiento sindical. La Convención Nacional de Trabajadores (CNT)", los autores transcriben fragmentos de documentación producida por los servicios de represión (en especial la Dirección Nacional de Información e Inteligencia -DNII-). Por tanto, este trabajo representa una importante base informativa para analizar la política dictatorial hacia la militancia sindical y la clase trabajadora tendiente a su represión y disciplinamiento.

La lectura de las fuentes seleccionadas permite visualizar distintos focos de activismo gremial a lo largo del período. Así, los agentes de inteligencia identificaron acciones de "sabotaje", "asonadas", reuniones clandestinas de militantes sindicales, asambleas en espacios laborales, reclamos de reintegro de trabajadores despedidos y reparto de volantes.

En el discurso de los agentes productores de la documentación se evidencia una permanente preocupación por diferenciar a los "subversivos", o sea los "sindicalistas" que habrían cooptado a las organizaciones sindicales, de los "trabajadores", quienes en realidad estarían de acuerdo con el modelo de país propuesto por el gobierno de facto.

A través de la vigilancia el régimen conocía o presumía la reorganización del movimiento sindical. Por ejemplo, se identificó la existencia de "comités de fábrica” a partir de 1974 en los que se habrían expresado distintas tendencias ideológicas; también se informó sobre las actividades desplegadas por las pocas organizaciones sindicales que no habían sido ilegalizadas, como por ejemplo ASU.

En este sentido cabe destacar que quienes elaboraban los informes interpretaban casi toda acción de organización sindical como producto de "maquiavélicos" planes urdidos por la "subversión”, específicamente la CNT. Los investigadores de la UdelaR afirman que en varios documentos de inteligencia "aparecen muchas listas con 'elementos izquierdistas' que operaban en cada fábrica, así como la filiación de los miembros de los sindicatos, que aún se mantenían en la legalidad.”

El lenguaje empleado por los agentes que realizaban los registros, signado por terminología militar, debe ser matizado, así como también el posible sobredimensionamiento o subrepresentación de algunas acciones. De todos modos, la sola sistematización de estos datos plantea pistas para rastrear esas acciones. Será necesario evaluar, a partir del cruzamiento con otras fuentes, el alcance de estos materiales generados en el ámbito represivo. 
Finalmente, es de destacar que uno de los principales aportes de esta investigación es la cuantificación y caracterización de los sindicalistas detenidos y desaparecidos, aunque reconocen que "la masividad de la detención de militantes hace muy difícil su cuantificación exacta." Hubo "oleadas represivas cíclicas" que en determinados momentos llegaron a "casi inmovilizar la resistencia de los sindicatos". A pesar de ello, y luego de advertir que seguramente se trate de materiales incompletos, presentan dos listados confeccionados en base a una diversidad de acervos documentales. En el primero se incluyen datos de más de ochocientos detenidos, como ser nombre completo, afiliación sindical, fecha de detención y de liberación (p. 233). El segundo es un "breve listado" de diecinueve militantes sindicales asesinados o desaparecidos en Uruguay, y veinte en Argentina. (pp. 234-238). Si tenemos presente que el número de detenidos desaparecidos uruguayos asciende a 196, los "sindicalistas" representarían una quinta parte.

Sabemos que en muchos casos "cayeron" por su militancia política, pero no resulta descabellado pensar que su carácter de activistas gremiales fuera causante de la persecución de la que fueron objeto.

Dentro de las fuentes inéditas producidas por el Estado mencionaremos tres conjuntos. En la Biblioteca Nacional hay distinta documentación del régimen que, más allá de las intenciones propagandísticas que hayan sustentado su producción, puede aportar algunos indicios respecto a la situación de los trabajadores y sindicatos en el período. Por ejemplo se encuentran memorias y balances de empresas y servicios públicos como la Administración Nacional de Correos. También hay documentación de distintos organismos vinculados con la seguridad social (área del Estado que sufrió importantes transformaciones en el período) que dan cuenta de los montos destinados en la materia en todo el país y por sectores de la producción y servicios. El relevamiento y cruzamiento de los datos que aportan este tipo de fuentes, con las debidas precauciones, podría ser un insumo para iniciar una caracterización más pormenorizada de la fuerza de trabajo en el período. Además de profundizar el conocimiento sobre las políticas del régimen destinadas a la clase trabajadora, su aplicación concreta y las respuestas sociales. El trabajo de Morón fue realizado en base a documentación del MTSS que en la actualidad no es accesible.

Cabe mencionar, por otra parte, que en el año 2009 el Archivo General de la Nación recibió documentación de la Oficina laboral del Estado Mayor Conjunto (ESMACO). Esta oficina se creó en 1974 y tenía como cometido encargarse de todos los asuntos laborales que surgieran "cualquiera fuera su origen" (Rico, 2008, p. 241). Aún estamos en gestiones para consultar este fondo del que el AGN tiene especiales resguardos ante la consulta pública por contener información sensible, pero de acuerdo a las referencias citadas en la investigación desarrollada por Rico (2008) y las menciones realizadas en la ponencia de Morón (2003) se puede suponer que representa un conjunto documental de relevancia para identificar, describir y analizar la conflictividad obrero-patronal de la época y otros asuntos.

Por último, destacamos que en 2018 el CEIU de la FHCE-UdelaR recibió en soporte digital parte del acervo documental de la DNII. Con la simple observación del inventario (disponible en la web) se encuentran numerosas referencias al mundo sindical y a los trabajadores; dentro de la que hay una carpeta exclusivamente dedicada al SUNCA. Si bien aún no se ha accedido a esta documentación inferimos que también puede significar un aporte que deberá ser debidamente ponderado en el marco de ulteriores etapas de la investigación en curso. Para esto resultará clave la consideración de experiencias previas de investigación basadas en documentación de este tipo en Uruguay y la región por las particularidades que presenta.

\section{Otros repositorios}

En la web de la OIT se encuentran transcripciones de las intervenciones de delegados uruguayos por las patronales, los obreros y el gobierno en asambleas anuales del organismo durante el período de facto. Estas informan sobre la postura del gobierno frente a cuestionamientos en materia de libertad sindical, así como también respecto a denuncias sobre el asunto realizadas por delegados de diversos países o de la "CNT en el Exterior". 
En el trabajo "Relevamiento de archivos y repositorios documentales sobre derechos humanos en Uruguay” la Dra. Vania Markarian (2007) presenta una minuciosa descripción de distintos conjuntos documentales ubicados dentro y fuera del país que podrían aportar a la temática que aquí tratamos. Entre estos destacamos el de la ASU, del Departamento de Historia del Uruguay de la FHCE ("Comisión nacional de destituidos", la Colección "Miguel Feldman" y la del Sindicato de Trabajadores de la Educación Privada -SINTEP-), de "Madres y familiares de detenidos desaparecidos", y del Servicio de Paz y Justicia. Lamentablemente son escasos los instrumentos de descripción de estos y otros repositorios mencionados por la autora, por lo que es difícil saber con precisión qué tipo de documentación tienen. Sólo con un sistemático proceso de relevamiento se podrá ponderar la relevancia de las fuentes en estos preservadas.

\section{ConcLusión}

El conocimiento acerca de la situación de los trabajadores y los sindicatos en dictadura ha dado importantes pasos en los últimos quince años. La etapa abierta hacia 2005 con el inicio de un gobierno de nuevo signo político que prometió dar respuesta a los reclamos de verdad y justicia (con incuestionables aunque magros resultados) coincide con estos avances.

Se comenzó a poner foco en aspectos parciales a través de la observación de las peripecias que habrían vivido las distintas organizaciones sindicales. Se accedió a otras fuentes y se registró el testimonio de más actores involucrados. De todos modos, entendemos que aún queda mucho por hacer. Quizá las dificultades en el acceso a importantes series de fuentes producidas por distintos organismos del Estado hayan significado un freno a estas iniciativas que siguen utilizando más o menos los mismos recursos informativos.

El esfuerzo que hemos emprendido en tratar de sistematizar y analizar la bibliografía (no exclusivamente historiográfica) nos ha planteado nuevas interrogantes y ha abierto nuevos horizontes respecto a las propuestas originales del proyecto de investigación que venimos desarrollando. Así hemos pasado de pretender investigar la "acción sindical" a través de casos, a sumar interrogantes que nos conducen a un mayor acercamiento a la realidad de los trabajadores y las transformaciones que sufrieron en el período. Por tanto ya no estamos observando exclusivamente el derrotero de la militancia sindical clandestina y sus intentos de organización, sino que nos preguntamos, por ejemplo, por las condiciones laborales y salariales de los trabajadores que pudieran haber motivado el accionar colectivo independientemente de la presencia de militantes sindicales "orgánicos". A través de la diversidad de fuentes documentales (presuntamente) accesibles en la actualidad creemos que podremos avanzar en ese sentido.

\section{ReFERENCIAS}

Alfonso, E. y Wschebor, I. (2000). El hombre solo es dueño de las palabras que no pronuncia (Trabajo final Seminario "Aproximaciones al estudio histórico del Uruguay reciente", inédito). Montevideo: CEIU-FHCE-UDELAR.

Alvarez, S. (2016). Épica, memoria e Historia. Pensando al Sindicato único nacional de la construcción y anexos (SUNCA) durante la última dictadura uruguaya. Ponencia presentada en la Mesa "Vidas partidas" del XII Encuentro Nacional. IV Congreso Internacional de Historia Oral de Argentina; Asociación de Historia Oral de la República Argentina. Tucumán.

Alvarez, S. y Sosa, A. (2014a). Haciéndoles "gambetas" a la represión: itinerarios del SUNCA de la post-huelga a la reafiliación. En Construyendo resistencia: el SUNCA durante la dictadura (1973-1985) [fasc. 1]. Montevideo: SUNCA - UDELAR - FHCE- CEIU.

Alvarez, S. y Sosa, A. (2014b). Valor y firmeza: las acciones del año 1974 y el paro del 9 de octubre. En Construyendo resistencia: el SUNCA durante la dictadura (1973-1985) [fasc. 2]. Montevideo: SUNCA - UDELAR - FHCECEIU. 
Alvarez, S. y Sosa, A. (2014c). Dando la primera batalla: el SUNCA en la huelga general. En Construyendo resistencia: el SUNCA durante la dictadura (1973-1985) [fasc. 3], Montevideo: SUNCA - UDELAR - FHCE- CEIU.

Alvarez, S. y Sosa, Á. (2015). Destellos en la oscuridad: militancia clandestina del SUNCA en los años de plomo (1975-1983). En Construyendo resistencia: el SUNCA durante la dictadura (1973-1985) [fasc. 4]. Montevideo: SUNCA - UDELAR - FHCE- CEIU.

Alvarez, S. y Sosa, Á. (2017). Abriendo las puertas de la libertad: el PRO-SUNCA y la reconstrucción del movimiento obrero (1975-1985). En Construyendo resistencia: el SUNCA durante la dictadura (1973-1985) [fasc. 5]. Montevideo: SUNCA - UDELAR - FHCE- CEIU.

Alvarez, S., Cuello, F. y Polloni Porras, A. (2014). La constancia de la lucha. Una Historia del Sindicato de Postales. Montevideo: UDELAR-PIT-CNT.

Autores Anónimos (2012). Gol del pueblo uruguayo. Montevideo: s/d.

Azar, P., García Repetto, U., Bertoni, R., Sanguinetti, C. y Sienra, M. (2009).¿De quiénes, para quiénes y para qué?: las finanzas públicas en el Uruguay del siglo XX. Montevideo: Fin de siglo.

Bohoslavsky, J. P. (2016). El negocio del terrorismo de Estado. Los cómplices económicos de la dictadura. Montevideo: Debate.

Bottaro, J. R. (1985). 25 años de movimiento sindical uruguayo. La vida de A.S.U. Montevideo: Avanzada.

Bouzas, C. (1997). La generación de Cuesta. Montevideo: s/d.

Bruschera, O. (1986). Las décadas infames. Análisis politico.1967- 1985. Montevideo: Linardi y Risso.

Caetano, G. y Rilla, J. (1987). Breve historia de la dictadura (1973-1985). Montevideo: EBO.

Camou, M y Maubrigades, S. (2006). El desafío de la productividad en la industria tradicional uruguaya. En M. Camou y R. Porrini (comps), Trabajo e historia en el Uruguay: investigaciones recientes. Montevideo: FCS-FHCE-CSIC.

Camou, M. y Maubrigades, S. (2007). Desigualdades de género en Uruguay en perspectiva histórica. Boletín de Historia Económica, 6, 33-49.

Cancela, W. y Melgar, A. (1985). El desarrollo frustrado. 30 años de economía uruguaya 1955-1985. Montevideo: CLAEH-EBO.

Carrió, M. (1987). País vaciado: dictadura y negociados (1973-1985). Montevideo: Monte sexto.

Chagas, J. y Trullen G. (1998). José D'Elía: memorias de la esperanza. Tomo II: Los años turbulentos 1965-1984. Montevideo: Trilce.

Chagas, J y Tornarelli, M. (1989). El sindicalismo uruguayo bajo la dictadura (1973-1984). Montevideo: Del Nuevo Mundo.

Ciganda, J. P. (2007). Sin desensillar... y hasta que aclare. La resistencia a la dictadura, AEBU, 1973-1984. Montevideo: Cauce.

Correa, J. (2018). Lo hicimos ayer, hoy y lo seguiremos haciendo. Montevideo: Fin de Siglo.

Cosse, G. (1985). Clase obrera, democracia y autoritarismo. En C. Filgueira (comp.), Los movimientos sociales en el Uruguay de hoy. Montevideo: EBO.

De Giorgi, Á. (2000). El caso uruguayo. En A. de Giorgi y S. Dominzain, Respuestas sindicales en Chile y Uruguay bajo las dictaduras y en los inicios de la democracia. Montevideo: UDELAR.

Demasi, C., Marchesi, A., Markarian, V., Rico A. y Yaffé, J. (2013). La dictadura cívico-militar. Uruguay 1973-1985. Montevideo: EBO.

Demasi, C., (2013). La evolución del campo político en la dictadura. En C. Demasi, A. Marchesi y S. Dominzain (coord.), Asi se forjó la historia. Acción sindical e identidad de los trabajadores metalúrgicos en Uruguay. Montevideo: Primero de Mayo-UDELAR.

Dominzain, S. (coord.) (2016). Asi se forjó la historia. Acción sindical e identidad de los trabajadores metalúrgicos en Uruguay. Montevideo: Primero de Mayo-UDELAR.

Dutrenit Bielous, S. (1994). El maremoto militar y el archipiélago partidario: Testimonios para la historia reciente de los partidos politicos uruguayos. Montevideo: ECS-Instituto Mora. 
Ermida Uriarte, O. y Grzetich, A. (1991). La estructura de la seguridad social, su evolución y situación actual. En La seguridad social en el Uruguay (pp. 71-118). Montevideo: FCU.

Errandonea, A. (1986). Sindicatos y democracia tutelada. Cuadernos de Marcha (Tercera Época), 9, 13-22.

Eyherabide, G. (1993). Historia de ASU. 33 Años de luch a popular. Montevideo: Contexto

Federación Uruguaya de la Salud (2015). 1965-2015. Federación Uruguaya de la Salud. Cinco décadas de lucha. Montevideo: Primero de Mayo.

Fernández Huidobro, E. (1995). El tejedor Héctor Rodríguez. Montevideo: Tae.

Fleitas, S. y Román, C. (2010). Evolución de la población económicamente activa en el siglo XX: un análisis de la estructura por sexo, edad y generaciones. Boletin de Historia económica, 9, 41-64.

García, L. (2010). Curtidores, organización y acción (fines del siglo XIX-1985). En R. Porrini Beracoechea (coord.). Del cuero "mal educado" y afines. Una historia de los obreros curtidores en el Uruguay (pp. 39-76). Montevideo: UDELAR.

García, L. (2016). Tiempos difíciles. En S. Dominzain (coord.). Asi se forjó la historia. Acción sindical e identidad de los trabajadores metalúrgicos en Uruguay (pp. 325-412). Montevideo: Primero de Mayo-UDELAR.

Gargiulo, M. (1984). Movimiento sindical y estabilidad democrática. Cuadernos del CLAEH, 20, 17-38.

Girona, M. y Siola, L. (2016). Historia y memoria de COFE. A 50 años de su fundación. Montevideo: COFE.

González, G. (2013). Una historia de FUCVAM. Montevideo: Trilce.

González, L. E. (1985). Transición y restauración democrática. Montevideo: CIESU.

González Sierra, Y. (1989). Reseña histórica del movimiento sindical uruguayo (1870-1984). Montevideo: CIEDURDATES.

Guillespie, C. (1997). Negociando la democracia. Politicos y generales en Uruguay. Montevideo: FCU.

Guerrini, A. (1989). "Nuevos movimientos sociales en la transición :el papel de FUCVAM en relación al sistema político y a los sindicatos". En E. Mazzei (comp.), Ensayos sobre el Uruguay de los 80: actores, situaciones e intereses (pp. 87-104). Montevideo: CIESU-Ediciones de la Banda Oriental. pp. 87-104.

Lanzaro, J. (1986). Sindicatos y sistema politico. Montevideo: FCU;

López Mercao, J. (2004). Una historia cervecera. Montevideo: Ediciones de la Memoria.

Macadar, L. (1982). Uruguay 1974-1980: ¿un nuevo ensayo de reajuste económico? Montevideo: Estudios CINVE. EBO.

Marchesi, A. y Markarian, V. (2012). Cinco décadas de estudios sobre la crisis, la democracia y el autoritarismo en Uruguay. Contemporánea, 3(3), 213-242.

Marchesi, A. y Markarian, V., Rico A., \& Yaffé J. (coords.) (2004). El Presente de la dictadura. Estudios y reflexiones a 30 años del golpe de Estado. Montevideo: Trilce.

Markarian, V. (2007). Relevamiento de archivos y repositorios documentales sobre derechos humanos en Uruguay. Montevideo: Archivo General de la Universidad.

Mariño, N., Noboa, C. y Parada, C. (2012). Las asignaciones familiares como salario indirecto: una aproximación a su incidencia distributiva en el largo plazo. Trabajo monográfico para obtener el título de Lic. en Economía, Montevideo: FCEA- UdelaR.

Masi, H. (1989). Vida de un metalúrgico: reportaje a Rosario Pietraroia. Montevideo: EPU.

Midaglia, C. (1989). "Interpretación preliminar de los nuevos movimientos sociales en Uruguay: FUCVAM y DDHH”. En E. Mazzei (comp.), Ensayos sobre el Uruguay de los 80: actores, situaciones e intereses (pp. 105-130). Montevideo: CIESU-Ediciones de la Banda Oriental.

Morón, A. (2003). El estado y la cuestión sindical en los inicios de la dictadura (1973- 75/76). En III Jornadas de Historia Económica. Asociación Uruguaya de Historia Económica, Montevideo. Recuperado de http:// www.audhe.org.uy/Jornadas_Internacionales_Hist_Econ/III_Jornadas/Simposios_III/18/Moron.pdf

Nahum, B. (coord.) (2012). 1960-2010. Medio siglo de historia uruguaya. Montevideo: EBO.

Notaro, J. (1984). La política económica en el Uruguay 1968-1984. Montevideo: CIEDUR. EBO. 
Notaro, J. (2003). La batalla que ganó la economía. En El Uruguay del Siglo XX. Tomo I. La Economía. Montevideo: EBO.

Pérez Antón, R. (1981). Sindicatos y democracia. Cuadernos del CLAEH, 20, 5-13.

Porrini, R. (2004). Una aproximación a la bibliografía e historiografía sobre la clase obrera y el movimiento obrero en el Uruguay. En R Porrini (comp.), Historia y memoria del mundo del trabajo. Montevideo: UDELAR, FHUCE, CSIC.

Porrini, R. (2018). Trabajadores y sindicatos uruguayos durante la dictadura (1973-1985). Consensos y resistencias. Recuperado de http://historiapolitica.com/datos/biblioteca/dicsind_porrini.pdf

Pucci, F. (1992). Sindicatos y negociación colectiva. Montevideo: CIESU.

Rico, Á. (coord.) (2008). Investigación histórica sobre la dictadura y el terrorismo en Uruguay (1973-1985). Tomo III. Montevideo: Udelar-CSIC-FHCE-CEIU.

Rico, Á., Demasi, C., Radakovich, R., Wschebor, I. y Sanguinetti, V. (2005). 15 dias que estremecieron al Uruguay. Montevideo: Fin de Siglo.

Rodríguez, U., Visconti, S., Chagas, J. y Trullen, G. (2006). El sindicalismo uruguayo. A 40 años del congreso de unificación. Montevideo: Taurus.

Rodríguez, U. y Visconti, S. (2008). Albañiles. Esos obreros del andamio. Montevideo: SUNCA.

Rodríguez, R., Chagas, J. y Ladra A. (1991).¿Réquiem para el movimiento sindical? Montevideo: IFIS-CAAS.

Ruíz Valente, H. (1992). Contribución a la historia de AEBU. Montevideo: s/d.

Sala de Tourón, L.y Landinelli,J. (1984). 50 años del movimiento obrero uruguayo. En P. González Casanova (coord.), Historia del movimiento obrero en América Latina. Vol. 4. México: Siglo Veintiuno.

Turiansky, W. (1987). Apuntes contra la desmemoria. Montevideo: Arca.

\section{Notas}

1 Este proyecto comenzó en el año 2018 y está enmarcado en el Programa de Iniciación a la investigación promovido por la Comisión sectorial de investigación científica de la Universidad de la República. Es tutoreado por el Mag. Carlos Demasi y se encuentra radicado en el Centro de Estudios Interdisciplinarios Uruguayos de la Facultad de Humanidades y Ciencias de la Educación (CEIU-FHCE-UdelaR).

2 El mismo, producto de un convenio entre la UDELAR y el SUNCA, se desarrolló entre los años 2013 y 2017, fue dirigido por el Mag. Carlos Demasi y estuvo radicado en el CEIU-FHCE-UDELAR

3 Esta fue impulsada por la estructura que aglutinaba a la inmensa mayoría de los sindicatos uruguayos: la Convención Nacional de Trabajadores CNT, y el apoyo de diversas organizaciones sociales y políticas. La huelga tuvo cierto éxito y logró paralizar sectores claves de la economía (como el transporte colectivo, la producción y distribución de combustible y electricidad, la banca, entre otros) y hacer visible una ruptura institucional que para muchos era difícil de apreciar desde el momento que la cabeza del Poder Ejecutivo y parte de su gabinete ministerial se mantenían en pie (Rico, Demasi, Radakovich, Wschebor y Sanguinetti, 2005).

4 Este había sido creado semanas atrás por un grupo de organizaciones sindicales nacidas a partir de la aprobación por parte del régimen de la Ley de Asociaciones Profesionales que, aunque muy restrictiva, permitió una reconstrucción legal del movimiento sindical uruguayo (Rodríguez, Chagas y Ladra, 1991; Chagas y Tornarelli, 1989, pp. 219-245)

5 Destacamos en este sentido los esfuerzos realizados por Javier Correa (2018) quien invita a superar la mirada "montevideocéntrica" respecto de la historia uruguaya en el período dictatorial.

6 La “Operación Morgan” fue una acción represiva impulsada por la dictadura uruguaya en coordinación con sus homónimas de la región, que tuvo como destinatarios al Partido Comunista de Uruguay (PCU), la Unión de la Juventud Comunista (UJC) y el Partido por la Victoria del Pueblo (PVP). Su saldo fue de cientos de militantes torturados y presos, así como decenas de asesinados y desaparecidos. La gran mayoría de estos militantes tenía doble militancia (partidaria y sindical) por lo que la nueva circunstancias impactó de modo directo en las posibilidades de que muchas estructuras sindicales pudieran actuar. Para más información de la "Operación Morgan” ver Rico, 2008, p. 28.

7 ASU nació como un movimiento de origen cristiano vinculado a la Confederación Latinoamericana Sindical Cristiana (CLASC). Fue fundado a comienzos del año 1960 en Montevideo. Tuvo inserción en varios sindicatos y sus militantes participaron activamente en el proceso de formación de la CNT. Durante la dictadura, a pesar de ser víctima de 
persecución y hostigamiento por parte del régimen, no fue formalmente ilegalizada, transformándose en un importante foco de actividad sindical y lucha antidictatorial.

8 El Dr. Enrique Etcheverry Stirling fue Ministro de Trabajo y Seguridad Social entre los años 1974 y 1979.

9 Hay que tener presente en este sentido el "manoseo" del que han sido objeto muchos de ellos habiendo ya testimoniado en el marco de causas judiciales. También lo que se imaginan respecto del "universitario": hemos detectado que depositan frente a esta figura una serie de expectativas que no siempre se pueden cumplir. Estos imaginarios atraviesan el relato que se va (co)-construyendo.

10 Actualmente el archivo del SUNCA cuenta con 123 unidades documentales vinculadas al período dictatorial. Este fue organizado de forma primaria en el marco del proyecto que estamos describiendo. Durante el presente año se mejorará su ordenamiento y se digitalizará a partir de un nuevo proyecto, en este caso de carácter estudiantil y radicado en el Servicio de Extensión Universitaria de la UdelaR.

11 FUCVAM fue fundada en el año 1970 por varias cooperativas de vivienda del interior y la capital del país que basaban su accionar en los principios de ayuda mutua y propiedad colectiva.

12 Boletín COVISUNCA-COVIADEOM, 1980.

13 Señalan que consultaron el Archivo de la Dirección Nacional de Información e Inteligencia; Archivo del Poder Legislativo (repartidos de la Comisión de Respeto a los Derechos Individuales, de Constitución y Códigos, de Educación y Cultura, del Interior, Defensa Nacional, y de Asuntos Administrativos del Consejo de Estado); Archivo General de la Nación y Archivo del Centro de Estudios Interdisciplinarios Uruguayos-Facultad de Humanidades y Ciencias de la Educación (colección "Hugo Cores", "Marta Ponce de León-Ricardo Vilaró", "Héctor Rodríguez" y "Daniel Baldassari”). Asimismo se realizaron gestiones para poder consultar documentación de la Oficina Laboral del Estado Mayor Conjunto (ESMACO) en el Archivo del Ministerio de Trabajo y Seguridad Social, que finalmente no pudo ser ubicada en dependencias de dicho ministerio. (p. 185) De todos modos señalan que "en el Archivo de la DNII hay varios documentos que hacen referencia a la actuación de este organismo en conflictos laborales puntuales" (p. 241). 